\title{
Innovative psychological and pedagogical technologies in teaching students of economics
}

\author{
Natalia Yudina ${ }^{1}$, and Natalia Naumova ${ }^{1, *}$ \\ ${ }^{1}$ Vladimir Branch of Financial University under the Government of the Russian Federation, 600037, Vladimir, Russia
}

\begin{abstract}
The article is focused on the psychological and pedagogical teaching technologies as those having important methodological principles including not only traditional systematic, information and action-related approaches, but also psychological follow-up in teaching and learning. The complex of pedagogical and psychological approaches seems highly innovative since it provides an important synergetic effect for the present-day teaching. The article considers the notion of psychological and pedagogical follow-up, its definition and contents as seemed to be more appropriate and correct in the view of the methodology of teaching, training and learning in higher vocational institutions. The empirical sample research material includes the analysis of activities set up and carried out in the Vladimir branch of Financial University under the Government of the Russian Federation since 2014, and the results of the student survey focused on their satisfaction in psychological assistance. The 2014-2019 experience of the university makes it possible to implement the innovative model of the psychological and pedagogical follow-up for students of economics which centers on the patterns of intellectual and personal identity of future professionals and helps to deal with psychological issues, improve the efficiency of teaching and learning and benefit from the socio-cultural experience in different educational contexts and environments.
\end{abstract}

\section{Introduction}

Teaching technologies are complicated and multi-aspect issues that makes it necessary to view them not only as structural integrity but as activity of their participants. This strategy seems to be an essential requirement for teaching technologies to function successfully and develop dynamically on the way to the target output.

The term "technology" ("science of craft", from Greek techne - "art, skill, cunning of hand"; and logos concept, doctrine) was introduced in ancient times. Traditionally, it referred to the collection of practical techniques, processes, skills and methods, used in the production of desired goods or services or in the accomplishment of scientific objectives. Technology emerged as practice. In the $20^{\text {th }}$ century, there used to be a considerable development of technology scientific issues, which were mostly focused on finding more sophisticated technological processes (E.V. Armensky, E.P. Velikhov, V.A. Vinokurov, V.M. Glushkov, G.M. Dobrov, B.M. Kedrov, G.I. Marchuk, D.I. Mendeleev, Yu.A. Paton, I.T. Frolov, etc.). In recent science, technology is considered as a complicated and multi-aspect phenomenon, required to describe and adopt a systematic approach.

One of the best definitions of technology enabling the shift to the teaching field was introduced by M. Markov [1] as follows: technology is the way to carry out a particular challenging process by means of dividing it into the system of consistent interrelated procedures and operations, which are likely to have a clear way of dealing and focused on high efficiency.

\section{Materials and methods}

In Russia, teaching technology has been initially established and developed as a pedagogical category in the works of such scholars as V.P. Bespalko, B.S. Gershunsky, G.R. Gromov, A.P. Ershov, V.A. Izvozchikov, M.V. Klarin, V.M. Monahov, N.N. Surtayeva, N.F. Talyzina, A.I. Uman, etc. Moreover, teaching technologies of vocational training and education are also being developed (e.g., S.Ya. Batyshev, A.P. Belyaeva, V.S. Zbarovky, T.I. Shamova, I.S. Yakimanskaya, etc.).

It should be noted that these scholars mainly turned to interpretation of theoretical and methodological issues, aspects of content modelling of various teaching technologies and developing their key concepts. However, modern science is not yet capable to give a clear description to the structure and functions of teaching technologies, their nature and essential features, ways of their transformation in each specific situation, complete construction theory and implementation of teaching technologies.

Moreover, there is a considerable difference between the ways teaching technologies are viewed and approached in home and foreign pedagogics. Foreign pedagogics, in particular, consider teaching technologies

\footnotetext{
*Corresponding author: natasha_nau@list.ru
} 
as being focused on the individualized and facilitated learning, management of conductive teaching driven by a hi-tech and e-environment, implementation of creative and innovative models of both teaching and learning (M. Clark, F. Percival and G. Ellington, D. Finn, P.D. Mitchell, etc.) [2]. In Russian pedagogics, technologization of teaching and learning is primarily viewed as the teaching system focused on the development of the learner's personality, flexible and humanistic ways of its management. Innovative technologies are determined here as individually centered (V.P. Bespalko, A.A. Verbitsky, P.Ya. Galperin, L.V. Zankov, M.V. Klarin, M.I. Machmutov, V.A. Slastenin, M.A. Choshanov, F. Yanushevich, etc.).

Technologization of education corelates with social and educational attitudes, social requirements to the development of the personal identity, new educational paradigms and concepts, common goals and contents of teaching, its specific nature, purpose and functions.

The objective of the present research is to identify psychological and pedagogical teaching technologies as those having important methodological principles including not only traditional systematic, information and action-related approaches, but also psychological follow-up in teaching and learning.

This set of pedagogical and psychological approaches as a complex of interrelated and interdependent methods is highly innovative since it makes it possible to provide important synergetic effect for the present-day teaching. The complex of various psychological and pedagogical methods and techniques is aimed at ensuring the best possible sociopsychological conditions and preserving psychological health and environment for the personal identity to be fully and harmoniously developed and shaped as the target of life activity.

Accordingly, in our view, the methodology of teaching, training and learning in higher vocational institutions is more appropriate and correct when considered as "psychological and pedagogical followup" focused on the patterns of intellectual and personal identity and its development through teaching, as well as dealing with psychological issues on how to improve the efficiency of teaching and learning and benefit from the socio-cultural experience in different educational contexts and environments [3].

The student psychological and pedagogical follow-up is aimed at establishing the environment that helps them make the following achievements:

1) adapt to the new challenges of successful higher vocational learning;

2) improve the efficiency of vocational learning;

3) sustain motivation to chosen profession and skillsbuilding in the field;

4) develop important features of professional identity due to the appropriate psychological assistance.

The current imbalance between the curriculum workload and functional abilities and powers of a human body results in the necessity to improve the methods of the psychological and pedagogical follow-up in higher vocational institutions. Accordingly, the imbalance is likely to cause disadaptation and disorders which will result in reducing the motivation to learning and professional activity in the future, failures of interpersonal interaction, multiple health complaints and ill tolerance for curriculum workload $[4,5]$.

The empirical sample research material includes the analysis of the range of activities that have been set up and carried out in the Vladimir branch of Financial University under the Government of the Russian Federation (Vladimir, Russia) for five years, since 2014, as well as the results of the student survey focused on their satisfaction in psychological assistance and counselling in different stages of their study in the higher vocational institution.

\section{Results}

The results of the survey for Bachelor's degree students in the educational program 38.03.01 "Economics" in the Vladimir branch of Financial University under the Government of the Russian Federation, focused on their satisfaction in psychological assistance and counselling in different stages of their study in the higher vocational institution, show that 40-60 per cent of freshmen consider psychological assistance highly important to overcome fear and depression in the pre-examination session, entry into the new university community, social cohesion of the academic group and solutions of individual problems $[6,7]$.

In fact, difficulties arise not only in the initial stage of the study (the first two semesters), when freshmen are adapting to the specificities and new requirements of the university academic activity, living conditions, new interpersonal interactions with fellow students, senior students, teachers, new labour and rest routine, etc. Students of economics indicate that they are likely to face hardships relating to the psychological imbalance even in the subsequent academic stages of their study in the university.

A considerable number of second- and third-year students admit the loss of interest in learning and reduction of learning motivation. In the final stage of study in the university, especially after undergoing occupational training, the difference between the desirable and achievable level of professional knowledge and skills, individual right to self-categorization of professional career, becomes particularly relevant. Very often, the output of this reflexive analysis results in applying for psychological assistance [8].

It therefore seems reasonable to include into the system of psychological and pedagogical follow-up not only the assessment of the individual adapting abilities or psychological assistance in certain stages of a person's study in the university, but also the development of professional skills important for an expert in his/her future activity.

Following this presentation, during 2014-2019 there has been a new system of psychological and pedagogical follow-up for students of economics for it being applied in each academic year in the Vladimir branch of 
Financial University under the Government of the Russian Federation.

It includes the complex of activities, psychological training and psychological-pedagogical classes with the purpose to maintain and boost motivation attitudes to the chosen professional activity as a future expert in the field, as well as to develop individual abilities and psychological skills important for a successful professional performance. The list of activities includes [9]:

1) dynamic psychological monitoring with the focus on individual features of students at different stages of their study;

2) mental and emotional state modelling with the focus on challenges of the professional learning and interpersonal relationship concerns in a student group;

3) development of individual professional abilities and skills important for a successful professional performance.

The structural diagram of the psychological and pedagogical follow-up for students of economics shows several blocks.

- Psychological evaluation of first-year students:

1) document screening, interviews with freshmen;

2) individual screening and testing relating to adaptation activities and based on psychological and diagnostical methods;

3) training of teachers and group supervisors with respect to the results of students' individual interviews and psychological surveys, recommendations for individual guidance;

- Psychological monitoring:

4) annual socio-psychological screening and psychological testing of freshmen and senior students at the end of the first semester;

5) detailed psychological screening of students falling behind and having instable motivation attitudes in learning;

6) psychological assistance to students with life challenges and concerns;

7) detailed screening of undergraduates ahead of the occupational training;

- Psychological guidance and counselling:

8) professional guidance;

9) undergraduate supervision during the occupational training with the focus on professional skills;

- Motivation development and modelling of individual professional abilities and skills with students of economics:

10) complex of training classes in the run of the learning process.

\section{Discussion}

The psychological and pedagogical follow-up for students of economics in the Vladimir branch of Financial University under the Government of the Russian Federation starts since the very first days they have entered the university. The results of the 2014-2019 psychological screening and multi-level individual survey "Adaptability" of first-year Bachelor's degree students of economics showed the insufficiency and deficit of their adaptation abilities.

In particular, the indicators of moral and normative features (M) of students are likely to meet the standards, whereas the indicators of their neuro-psychiatric sustainability (NB) and communicative skills (C) differ by $p<0,05$ from the nominal value (Table 1 ). These indicators are considered as the main and key criteria of successful academic and professional adaptation, thus making it possible to demonstrate that a part of freshmen is likely to overcome challenges of their sociopsychological adaptation to the learning and academic environment during their study in the university $[10,11]$.

Table 1. Comparative analysis of student screening in the initial and final stages of their study in the Vladimir branch of Financial University under the Government of the Russian Federation (in a "standard ten" scale).

\begin{tabular}{|c|c|c|c|c|}
\hline Features & 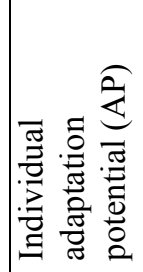 & 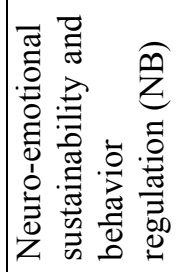 & 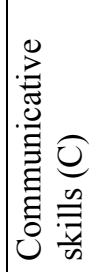 & 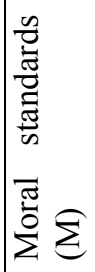 \\
\hline $\begin{array}{l}\text { First-year } \\
\text { students }\end{array}$ & 4,8 & 4,5 & 4,2 & 5,8 \\
\hline $\begin{array}{l}\text { Under- } \\
\text { graduates }\end{array}$ & 6,6 & 6,2 & 6,5 & 7,2 \\
\hline $\begin{array}{l}\text { Standards } \\
\text { and norms }\end{array}$ & 5,5 & 5,5 & 5,5 & 5,5 \\
\hline
\end{tabular}

Accordingly, entering the university is the time when assessments start and include reviews of students' personal history, survey, polling and individual interviews, which help identify the nature of personal development and upbringing before entering, key reasons of career choice, interests and preferences, perspectives for the future, etc.

The adaptation of freshmen takes place in the N.E. Zhukovsky Memorial Museum House (Sobinsky district, Vladimir region) and lasts about the first month since the beginning of the academic life. It is here when the individual screening and testing based on psychological and diagnostical methods is carried out. Screening applies specialized diagnostic methodology, including psychological testing, and is usually focused on identifying people affected by pathologies or risk factors of its development.

The results of students' personal history study and the data collected during the individual interviews and psychological screening are brought to the teachers of the administering departments, deputy directors for curriculum and education, social workers and group supervisors in order to take these statistics into account in training and teaching and guiding nonresidential students. The latter relates to the necessity of getting adapted not only to the new university and academic environment, networking and student community, but also to some other stress-inducing social factors, as 
follows: dormitory accommodation; independent planning of study, work and leisure free from parental control; management of financial and budgetary matters; self-catering, laundry, personal hygiene; communication and interaction with roommates, senior students of both genders, etc.

Freshmen group supervisors repeatedly hold private individual interviews focused on revealing adaptation matters and providing students with timely psychological counselling and guiding.

Further annual psychological monitoring is provided in the end of the study using the standardized methods and techniques, socio-psychological and psychological testing with the purpose to study the dynamics of students' personal attitudes and individual motivation at the end of the first semester of each academic year. The monitoring outcomes help to evaluate the following aspects:

- students' individual psychological attitudes and their development dynamics;

- dynamics of motivation objectives, learning purposes and perspectives of professional activity as an economist;

- nature of personal interrelations and academic group matters, attitudes, unity and team spirit;

- likelihood of addictive behaviour.

With a view to optimize personal interrelations during the study in the Vladimir branch of Financial University under the Government of the Russian Federation, the university curriculum of the educational program 38.03.01 "Economics" then provides communicative competence and business communication trainings. Beside training classes, the professional-psychological follow-up includes now traditional multiple events and activities that maintain high professional motivation of students:

1) vocational and career-oriented Olympiads, quizzes and contests:

- Youth International Social Advertising and AntiCorruption Contest "Let's fight corruption together!";

- International Insurance Olympiad;

- Regional contest "Vladimir Young Leaders";

- Regional contest "Economist career is my calling";

- Inter-Academic Tax Olympiad;

- Inter-Academic Scientific and Social Lay-Out Contest "From scientific concepts to social lay-outs";

- Olympiad "Mission possible! Financier is your calling";

- Olympiad of Glavbuch System;

- Financial Quiz;

- Quiz "When your career is state (municipal) manager";

- Quiz "Economics ABCs";

- Mental game "Economy life-hacks";

2) round tables, workshops and seminars with the representatives of business structures, invited speakers and experts, Financial University graduates:

- Round table "Occupations at the Vladimir region labour market. Issues and perspectives for the youth" in cooperation with the "Vladimir Region Youth in Government";
- Round table "Youth scientific, research and social projects: outputs efficiency";

- seminar "Principles of project management";

- workshop "Individual and professional efficiency: system and life-hacks";

- meetings with invited speakers and experts (e.g.: with top-manager of Siemens Ltd Wolfram Howein (Germany); CEO of "Lausha Real Estate" Ltd Jurgen Shellenberger; the officer in charge of ErlangenVladimir partnership Peter Steger; vice-president and head of the Vladimir branch of "MinBank" PJSC Alexander Krutov; option dealer Ilia Buturlin);

- scheduled meetings with private business representatives ("RZD" Ltd, "Consultant Centre" Ltd, "VTB Insurance" Ltd), leading regional banking structures (Vladimir branch of "Sberbank Russia" PJSC, Vladimir branch of "MinBank" PJSC, Vladimir regional branch of "Rosselkhozbank" AO, Vladimir branch of "Home Credit and Finance Bank" Ltd);

- scheduled public lectures of the Vladimir branch university teachers and specialists;

3) thematic scientific and practical conferences of municipal, regional, federal and international level:

- International Scientific Student Congress "Project for Russia";

- All-Russia Youth Educational Forum "Territory of senses on the Klyazma river";

- All-Russia Student Forum "From concept to business";

- Regional Educational Festival "Science marathon";

- Vladimir Inter-regional Economic Forum;

- Annual Vladimir Tax Forum "Taxes: modern view";

- Annual Scientific and Practical Conference "Topical issues of taxation theory and practice";

4) career fairs and career days aimed at seeking student and graduate job opportunities and promoting university partner and potential employer mutual interrelation and cooperation:

- study options fair "My career choices";

- study options exhibition fair "Your career choice";

- Career Day;

5) thematic social and public activities:

- All-Russia Educational Event "All-Russia economics dictation" in cooperation with Russian Free Economic Society;

- Financial Literacy Dictation;

- cooperation of the Vladimir branch of Financial University under the Government of the Russian Federation with the Youth Duma under the Legislative Assembly of the Vladimir region;

- Vocational guidance student sector "Financier is your calling!"’.

The psychological-pedagogical follow-up experience shows that special attention should be paid to undergraduate students ahead of the occupational training, since it is the first time they are going to try their hand in their independent vocational activity with the obvious lack of practical experience of working for operating businesses. Most students seem likely to suffer from the excessive mental and emotional stress. The fact is taken into account, undergraduates are welcomed to 
undergo the pre-occupational training express-screening supplemented by the results of the questionnaire surveys. The symptoms having been diagnosed with the students, the university carries out special activities and psychological correction implementing the methods and techniques of reasonable and positive psychotherapy and psychosomatic regulation.

Moreover, psychological and pedagogical follow-up includes supervision activities and guidance of senior and undergraduate students during the occupational training. Supervision stands for professional assistance provided to students by a more experienced colleague focused on his personal professional achievements and a better quality of his work. The main supervision goal is to help a future specialist get more successful in his/her practical experience, develop his/her professional competence. Supervision includes three key elements: training, support and guidance of future specialists. Supervision provides solutions and tutorial support for specific issues and real-life matters having been precedential at the operating businesses.

For the economics student and youth interests, rights, creative potential, social and cultural lay-outs being developed and promoted, the Vladimir branch of Financial University under the Government of the Russian Federation has a regular Student Counsel aimed at the development of the student self-government, its Chairman being the member of the Academic Board and functioning as a mediator between the student community, university teaching staff and the branch authorities.

\section{Conclusion}

Psychological counselling and correction in the system of innovative psychological and pedagogical follow-up for students of economics in the Vladimir branch of Financial University under the Government of the Russian Federation play a highly important role in preserving and maintaining the students' health and morale during their study in the university. Accordingly, these activities make it possible for students to identify their individual strengths and weaknesses and get recommendations for development of their professionally vital features and skills important for successful career development in the future.

Innovative methods and techniques of the psychological and pedagogical follow-up have proved their efficiency. The results of the 2014-2019 comparative analysis (Table 1) demonstrate the positive outputs in the activities of the psychological and pedagogical follow-up approach. In particular, the statistics of the multi-level individual survey "Adaptability" shows the increase of the partial scale indicators revealing the better level of neuro-psychiatric sustainability (MB), communicative skills (C) and moral principles (M), as well as the common indicator of the individual adaptation potential (AP) with the undergraduate students.
In sum, the innovative system of psychological and pedagogical follow-up for students of economics in the Vladimir branch of Financial University under the Government of the Russian Federation, based on the systematic activity approach and focused on the development of professional individuality, has proved itself valid and possible to be built due to the cooperation of group supervisors, teaching staff, senior and undergraduate students, and well-scheduled curriculum, educational, creative and vocational training activities of future financial specialists.

\section{References}

1. M. Markov, Technology and efficiency of social management (Bukinist, Moscow, 1982)

2. G.E. Hall, L.F. Quinn, D.M. Gollnick, Introduction to teaching. Making a difference in student learning (SAGE Publications, USA, 2016).

3. E.I. Pilyugina, O.V. Berezhnova, Psychological follow-up in the individual and professional development of a university student, Young scientist 10, 289-291 (2012).

4. G.V. Bezyuleva, Psychological and pedagogical follow-up in the professional adaptation of high school and university students, 63, Monograph (Moscow Psychology-Social Institute, Moscow, 2008).

5. T.N. Berezina, Emotional risk-free educational environment and true emotions, Bulletin of Moscow Region State University. Psychological sciences 3, 16-22 (2013).

6. M.V. Moskova, Personal factors of student emotional disadaptation, Doctoral theses in Psychology (2008).

7. A.A. Smirnov, N.G. Zhivayev, Levels of subjective control and student adaptation, Bulletin of P.G. Demidov Yaroslavl State University. The Humanities 6, 53-58 (2008).

8. L.S. Elgina, Student social adaptation, Bulletin of Buryat State University 5, 162-166 (2010).

9. G.V. Bezyuleva, Psychological and pedagogical follow-up in the professional adaptation of high school and university students, 76, Monograph (Moscow Psychology-Social Institute, Moscow, 2008).

10. J. Hunsley, Psychological testing and psychological assessment: a closer examination, Volume 57, American Psychologist 2, 139-140 (2002).

11. P. Miquelon, R.J. Vallerand, F.M.E. Grouzet, G. Cardinal, Perfectionism, academic motivation, and psychological adjustment: an integrative model, Volume 31, Personality and social psychology bulletin 7, 913-924 (2005). 